
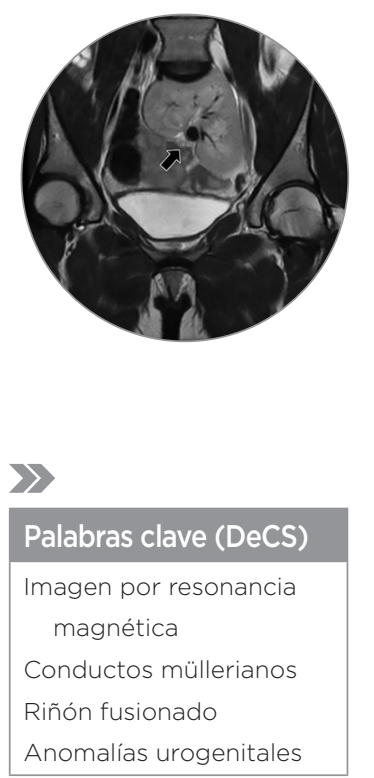

\section{Key words (MeSH)}

Magnetic resonance

$$
\text { imaging }
$$

Mullerian ducts

Fused kidney

Urogenital abnormalities
'Residente de Radiología e Imágenes diagnósticas, cuarto año. Universidad del Norte, Hospital Universidad del Norte. Barranquilla, Colombia.

${ }^{2}$ Radiólogo Pediatra, Departamento de Radiología e Imágenes Diagnósticas. Nicklaus Children's Hospital. Miami, USA

\title{
Síndrome de Mayer-Rokitansky- Kuster-Hauser asociado a riñón pélvico fusionado. Presentación de caso
}

\author{
Mayer-Rokitansky-Kuster-Hauser Syndrome with Pelvic Fused Kidney. \\ A Case Report
}

\author{
Laura Palacio Uribe \\ Julio Egusquiza \\ Seth Crapp $^{2}$
}

\section{Resumen}

Se presenta un caso de Síndrome de Mayer-Rokitansky-Kuster-Hauser tipo II asociado a riñón pélvico fusionado diagnosticado por resonancia magnética. Si bien el síndrome de MRKH es una entidad bien reconocida asociada a diversas malformaciones de las estructuras müllerianas, en esta revisión de la literatura no se han encontrado casos similares asociados específicamente a ectopia renal pélvica fusionada. Se hará una breve revisión del síndrome y sus principales hallazgos por imagen.

\section{Summary}

We present a case of Mayer-Rokitansky-Kuster-Hauser Syndrome type II associated with fused pelvic kidneys diagnosed by MRI. While MRKH Syndrome is a well-recognized entity associated with various Mullerian structure malformations, we did not find any similar cases in our review of the literature associated specifically with fused pelvic kidney ectopy. A brief review of the syndrome and its main findings will be done by imaging.

\section{Introducción}

El síndrome de Mayer-Rokitansky-Kuster-Hauser (MRKH) constituye una anomalía congénita poco frecuente de los conductos müllerianos, que se caracteriza por la ausencia del útero y los dos tercios superiores de la vagina, con una incidencia de 1 por cada 4.000 a 5.000 nacimientos de sexo femenino (1). Las pacientes tienen ovarios funcionales normales y, por lo tanto, una apariencia fenotípica normal de los genitales externos, mientras que la vagina ocasionalmente puede constituir un pequeño bolsillo de 2 a 4 centímetros de longitud o estar completamente ausente (2).

El síndrome de MRKH está dividido en dos subtipos dependiendo de si se encuentra aislado o asociado con otras malformaciones. El síndrome de MRKH tipo 1 hace referencia a la aplasia útero-vaginal aislada. El síndrome de MRKH tipo 2 hace referencia a una aplasia incompleta asociada a otras malformaciones, dentro de las cuales se han descrito malformaciones renales, esqueléticas y defectos de audición. Las anomalías renales descritas con mayor frecuencia en la literatura incluyen la agenesia renal unilateral, ectopia renal y riñón en herradura (1,3-5).

La presentación clínica típica es una mujer alrededor de los 16 años con amenorrea primaria. Estas pacientes presentan un fenotipo femenino normal con desarrollo de los caracteres sexuales secundarios debido a su función ovárica normal.

\section{Presentación del caso}

Paciente de sexo femenino de 16 años que consulta por amenorrea primaria sin ningún otro síntoma asociado. El examen físico revela apariencia normal de caracteres sexuales femeninos secundarios. Se realizó ultrasonido pélvico en el que no se encontraron el útero y los ovarios. Se obtuvieron imágenes por resonancia magnética (RM), revelando la ausencia de útero, cérvix y vagina proximal (figura 1) y la presencia de ovarios derecho (figura 2) e izquierdo (figura 3) en posición alta en la cavidad abdominal. Adicionalmente, se demostró riñón pélvico con dos unidades renales e hilios separados, con riñón pélvico ectópico fusionado (figura 4). También se identificó una anomalía de la segmentación del cuerpo vertebral de T11 consistente con vértebra en mariposa.

\section{Discusión}

Se ha establecido que el síndrome de MRKH tipo II se asocia con diversas anomalías renales, de las cuales se describen con mayor frecuencia en la literatura la agenesia renal unilateral, el riñón pélvico y el riñón en herradura (1,3-5).

En un estudio realizado por Hall-Craggs y colaboradores (4) en el que se realizó IRM a 52 pacientes con diagnóstico previo de síndrome de MRKH encontraron riñones anormales en 13 mujeres. Dentro de las anomalías renales descritas se encontraban la agenesia 


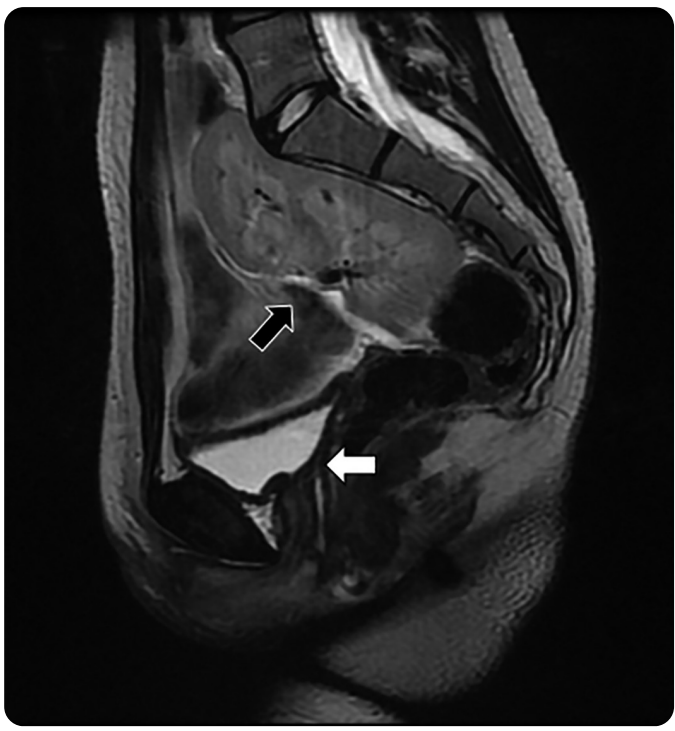

Figura 1. RM de pelvis, con información T2 sagital: riñón pélvico (flecha negra). Ausencia de útero, cérvix y vagina proximal (flecha blanca).

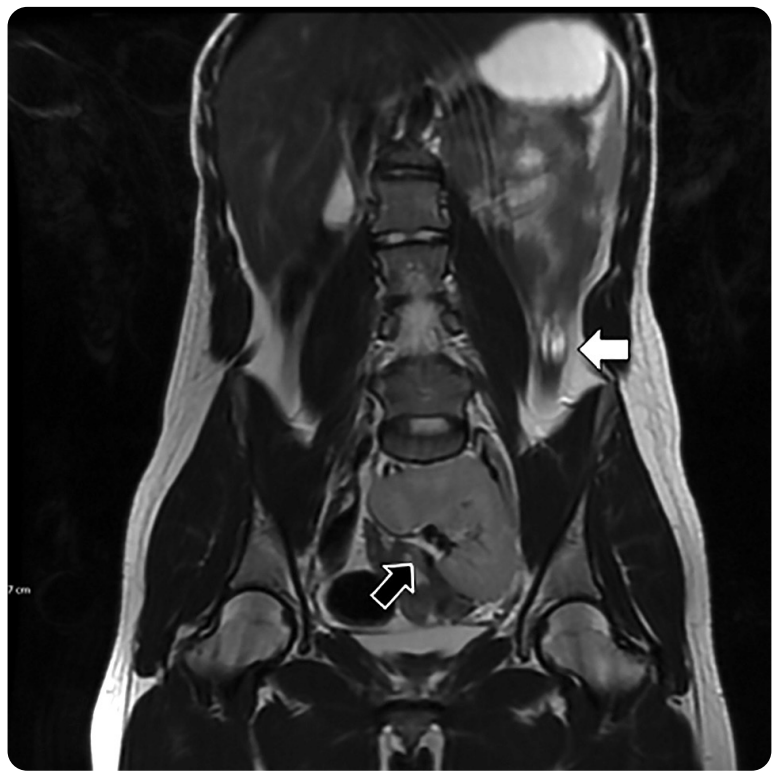

Figura 2. RM de pelvis con información T2 coronal: ovario derecho de posición alta (flecha blanca) y riñón pélvico fusionado (flecha negra).

renal, ptosis renal, riñón en herradura, riñón pélvico, riñón atrófico y cicatrices renales bilaterales. En otro estudio llevado a cabo por Oppelt y colaboradores (6) se les realizó RM a 53 pacientes con síndrome de $\mathrm{MRKH}$, en los que se encontraron riñones anormales en 19 mujeres. Las anomalías renales encontradas fueron: 12 casos de agenesia renal unilateral, 9 casos de riñón pélvico unilateral y dos riñones escleróticos.

Dentro de los diagnósticos diferenciales que se deben considerar se encuentra la aplasia müllerianas e hiperandrogenismo (síndrome WNT4) y el síndrome de insensibilidad a los andrógenos, en los que también está descrita la ausencia de útero y vagina superior: en el primero asociado a hiperandrogenismo y ovarios masculinizados, y en el segundo asociado a la presencia de testículos. Otro diagnóstico para tener en cuenta es la atresia vaginal aislada $(3,5,7)$.

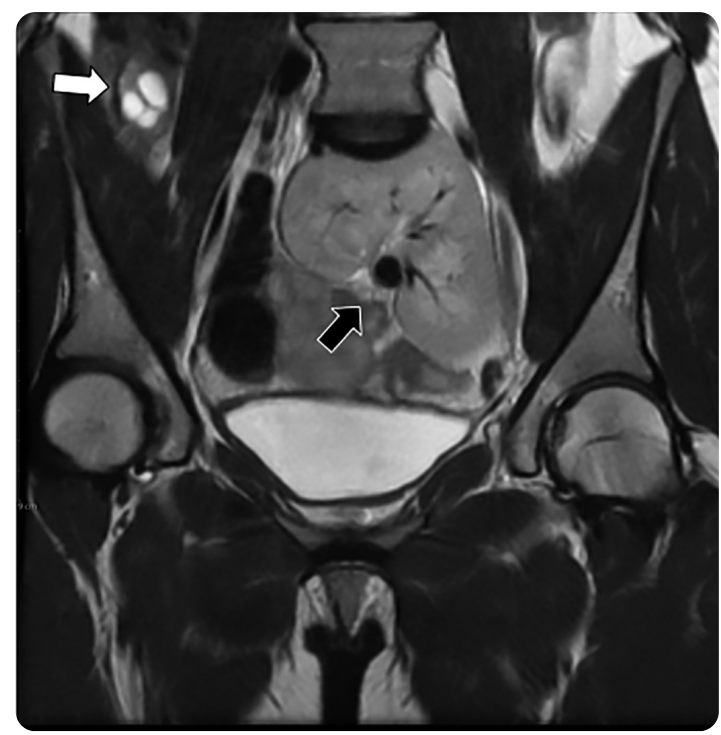

Figura 3. RM abdominopélvica con información T2 coronal: riñón pélvico fusionado (flecha negra), ausencia de útero y vagina, ovario izquierdo de posición alta (flecha blanca).

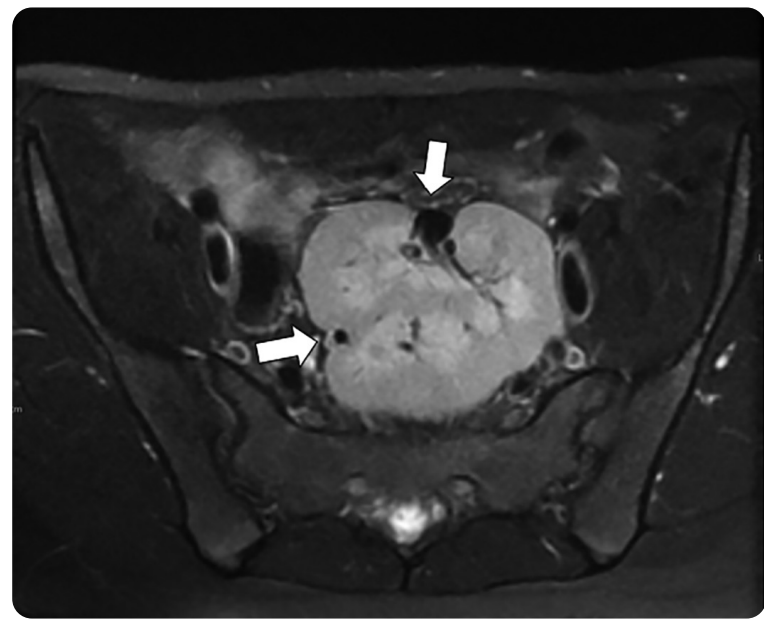

Figura 4. RM de pelvis secuencia STIR axial: riñón pélvico con dos unidades renales y dos hilios independientes (flechas blancas): riñón pélvico fusionado.

El tratamiento de esta condición se encuentra enfocado en la creación de una neovagina para lograr una vida sexual normal (inicialmente por métodos no quirúrgicos utilizando dilatadores vaginales $\mathrm{y}$, en caso de ser necesario, mediante procedimiento quirúrgico). Las pacientes que tengan deseo de fertilidad tienen la opción de recurrir a la fertilización in vitro con sus propios ovocitos y el útero de una madre subrogada. El pronóstico de esta condición es bueno; sin embargo, se recomienda acompañamiento psicológico por el estrés que pueda causar en la vida de la paciente $(2,3,4)$

A pesar de que esta entidad y su asociación con anomalías renales se encuentra ampliamente descrita en la literatura, presentamos un caso único en el que el síndrome de MRKH se encuentra asociado a ectopia renal pélvica fusionada. 


\section{Referencias}

1. Strübbe EH, Willemsen WN, Lemmens JA, et al. Mayer-Rokitansky-Kuster-Hauser syndrome: distinction between two forms based on excretory urographic, sonographic, and laparoscopic findings. Am J Roentgenol. 1993;160:331-4.

2. Giusti S, Fruzzetti E, Perini D, et al. Diagnosis of a variant of Mayer-Rokitansky-Kuster-Hauser syndrome: useful MRI findings. Abdominal Imaging. 2011;36(6):753-5.

3. Morcel K, Camborieux L, Guerrier D. Mayer-Rokitansky-Küster-Hauser (MRKH) syndrome. Orphanet J Rare Dis. 2007;2(1):13.

4. Hall-Craggs MA, Williams CE, Pattison SH, et al. Mayer-Rokitansky-Kuster-Hauser syndrome: diagnosis with MR imaging. Radiology. 2013;269(3):787-92.

5. Boruah DK, Sanyal S, Gogoi BB, et al. Spectrum of MRI appearance of MayerRokitansky-Kuster-Hauser (MRKH) syndrome in primary amenorrhea patients. JCDR. 2017;11(7):TC30

6. Oppelt P, Renner SP, Kellermann A, et al. Clinical aspects of Mayer-Rokitansky-Kuester-Hauser syndrome: recommendations for clinical diagnosis and staging. Human Reproduction. 2006;21(3):792-7.

7. Biason-Lauber A, Konrad D, et al. A WNT4 mutation associated with Müllerian-duct regression and virilization in a 46, XX woman. New Eng J Med. 2004;351(8):792-8.

\section{Correspondencia}

Laura Lucía Palacio

Universidad del Norte

Carrera 55 \# 82-166

Barranquilla, Colombia

laupalacio@gmail.com

Recibido para evaluación: 1 de febrero de 2020

Aceptado para publicación: 15 de marzo de 2020 